\title{
New Anthocyanin-Human Salivary Protein Complexes
}

\author{
Raúl Ferrer-Gallego, ${ }^{*}{ }^{\dagger \dagger}$ Susana Soares, $^{\dagger}$ Nuno Mateus, ${ }^{\dagger}$ Julián Rivas-Gonzalo, ${ }^{\ddagger}$ \\ M. Teresa Escribano-Bailón, ${ }^{\ddagger}$ and Victor de Freitas ${ }^{\dagger}$ \\ ${ }^{\dagger}$ REQUIMTE/LAQV, Departamento de Química e Bioquímica, Faculdade de Ciências, Universidade do Porto, Rua do Campo \\ Alegre, 687, 4169-007 Porto, Portugal \\ ‡Grupo de Investigación en Polifenoles, Unidad de Nutrición y Bromatología, Facultad de Farmacia, Universidad de Salamanca, \\ Campus Miguel de Unamuno, E 37007 Salamanca, Spain
}

Supporting Information

ABSTRACT: The interaction between phenolic compounds and salivary proteins is considered the basis of the poorly understood phenomenon of astringency. Furthermore, this interaction is an important factor in relation to their bioavailability. In this work, interactions between anthocyanin and human salivary protein fraction were studied by mass spectrometry (MALDI-TOF-MS and FIA-ESI-MS) and saturation-transfer difference (STD) NMR spectroscopy. Anthocyanins were able to interact with saliva proteins. The dissociation constant $\left(K_{\mathrm{D}}\right)$ between malvidin 3-glucoside and salivary proline-rich proteins was $1.92 \mathrm{mM}$ for the hemiketal form ( $\mathrm{pH} 3.4$ ) and $1.83 \mathrm{mM}$ for the flavylium cation ( $\mathrm{pH} \mathrm{1.0)}$. New soluble complexes between these salivary proteins and malvidin 3-glucoside were identified for the first time.

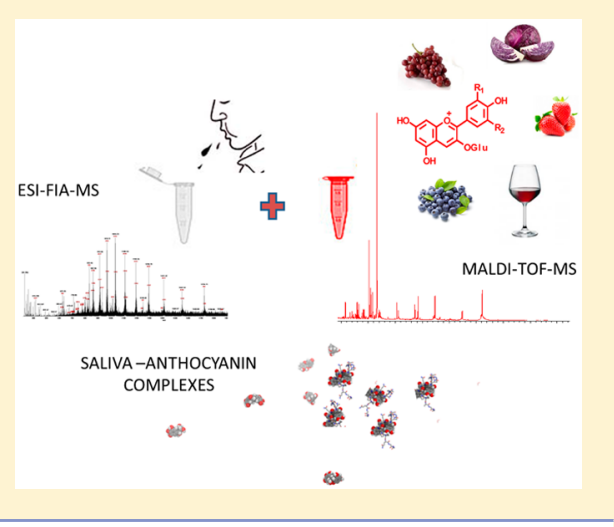

\section{INTRODUCTION}

Phenolic compounds play a major role in several organoleptic features of food and beverages, in particular for color, bitterness, and astringency. Anthocyanins are the most widespread group of polyphenols plant pigments and are mainly responsible for the red wine color. They are not usually directly linked to astringency sensation, ${ }^{1}$ although they may contribute to the bitterness of fruits. ${ }^{2}$

Astringency is a tactile sensation strongly related to the interaction between phenolic compounds and saliva proteins. ${ }^{3,4}$ As a result of this interaction process, soluble and insoluble salivary complexes can be formed. Evidence of the formation of insoluble complexes has been widely used to reveal astringent activity, whereas the role of soluble complexes remains unclear. $^{5-9}$

Saliva plays an important role in the oral cavity, namely lubrication, protection, and digestion. It is produced by sublingual, submandibular, parotid, and other minor salivary glands. Saliva is a very dilute fluid, composed of more than $99 \%$ water, the reminder consists of a mixture of electrolytes, immunoglobulins, enzymes, mucins and nitrogenous products. ${ }^{10}$ Saliva contains several peptide families like statherins, histatins, prolinerich proteins (basic, acidic and glycosylated) and cystatins. ${ }^{11}$ Proline-rich proteins (PRPs) are particularly abundant in human saliva and may constitute $70 \%$ of total secreted proteins in parotid glands. ${ }^{12,13}$ Many studies have focused on the interactions between this family of peptides and some phenolic compounds in order to understand the astringency perception, ${ }^{6,14-20}$ but little information exists about the interactions between natural pigments and salivary proteins. ${ }^{21}$
The global aim of this work is to provide valuable information to understand the interactions between anthocyanins and human saliva proteins, as well as in the formation of complexes. For this, anthocyanin-salivary proteins interactions were evaluated by mass spectrometry and saturation-transfer difference (STD) NMR spectroscopy.

Different anthocyanins (malvidin 3-glucoside, delphinidin 3-glucoside, cyanidin 3-glucoside and petunidin 3-glucoside) were mixed with human saliva and assessed by matrix-assisted laser desorption/ionization time-of-flight mass spectrometry (MALDI-TOF-MS). A purified fraction of saliva that mainly contained acidic PRPs was used in order to identify new soluble malvidin-salivary protein complexes by flow injection analysis (FIA) with electrospray ionization mass specrometry (ESI-MS). The strength of the interaction between malvidin 3-glucoside and the acidic PRPs (aPRPs) was characterized by STD NMR spectroscopy, and the dissociation constant $\left(K_{\mathrm{D}}\right)$ of the hemiketal form and the flavylium cation was obtained.

\section{MATERIALS AND METHODS}

2.1. Saliva Collection and Isolation. A pool of saliva was collected from six healthy nonsmoking volunteers ( 2 males and 4 females aged 22 to 32 years old). All subjects hold saliva inside their mouth for $10 \mathrm{~min}$ and spit it all at once. They were previously instructed to avoid food and beverages for at least $1 \mathrm{~h}$ before collection. Collection time was standardized about 2 p.m. to reduce concentration variability linked

Received: March 27, 2015

Revised: July 1, 2015

Published: July 10, 2015 
to circadian rhythms of secretion. ${ }^{12,22}$ Treated saliva (TS) and whole saliva (WS) were used for the experiments. Saliva was treated with trifluoroacetic acid (final concentration $0.1 \%$ ) and centrifuged $(8000 \mathrm{~g}$ for $5 \mathrm{~min}$ ), and whole saliva was nontreated and noncentrifuged. TS was evaluated before and after filtration (pore size $0.2 \mu \mathrm{m}$ ).

The isolation of the acidic PRP fraction was obtained from TS. For this, TS was dialyzed in a cellulose dyalisis membrane (MWCO: $3.5 \mathrm{kDa}$ ) for $24 \mathrm{~h}$ at $4{ }^{\circ} \mathrm{C}$ with stirring against deionized water. Water was changed periodically. After analysis, saliva was centrifuged, and the supernatant was freeze-dried. The lyophylized saliva was solubilized in the lowest possible volume of water. The acidic PRP fraction of salivary proteins was separated by HPLC as described elsewhere. ${ }^{23}$ This study was conducted according to the Declaration of Helsinki and was approved by the Ethics Committee of the Medical School of the University of Porto (EK84032011).

2.2. Anthocyanin Isolation. Anthocyanidin monoglucosides were isolated from Vitis vinifera L. cv. Tempranillo grape skins by semipreparative HPLC. Extraction was carried out three times using $\mathrm{MeOH} / 12 \mathrm{M} \mathrm{HCl}$ 999:1 (v/v), and the extracts were gathered and evaporated under vacuum at $30{ }^{\circ} \mathrm{C}$. The residue was redissolved in aqueous $\mathrm{HCl}(0.1 \mathrm{M}, \mathrm{pH} 1)$ and then loaded on a Sephadex LH-20 (Sigma-Aldrich, St. Louis, MO, USA) column $(30 \times 300 \mathrm{~mm})$, previously conditioned using the same aqueous $\mathrm{HCl}$ solution. Elution was carried out with the aqueous $\mathrm{HCl}$ solution, and different fractions were collected. Fractions were gathered and then freeze-dried to furnish a reddish purple powder. Anthocyanins purity $(>95 \%)$ was determined by HPLC-DAD-MS analysis.

2.3. MALDI-TOF-MS Analysis. TS was diluted in Milli-Q water (1:10 and 1:100) and analyzed before and after the interaction with malvidin 3-glucoside, cyanindin 3-glucoside, delphinidin 3-glucoside and petunidin 3-glucoside. The control condition was diluted saliva $(150 \mu \mathrm{L})$ and $(50 \mu \mathrm{L})$ Milli-Q water (final volume $200 \mu \mathrm{L})$. For the experiments, $50 \mu \mathrm{L}$ of anthocyanins $(1 \mathrm{mM}$ and $2 \mathrm{mM})$ were added to $150 \mu \mathrm{L}$ of diluted saliva to obtain the final volume of $200 \mu \mathrm{L}$ ( $\mathrm{pH} 3.8$ ). Samples were vortexed briefly and then allowed to stand for $30 \mathrm{~min}$. Samples were prepared and spotted in triplicate.

In order to optimize the mass spectrometry method, different matrices and preparation protocols were used following Bruker Daltonics recommendations. Thus, DHAP matrix $\left(2^{\prime}, 4^{\prime}\right.$, -dihydroxyacetophenone $)$ was prepared (1:1:1) with $2 \mu \mathrm{L}$ of TFA (2\%), $2 \mu \mathrm{L}$ of matrix (7.6 mg/ $375 \mu \mathrm{L}$ of ethanol) and $2 \mu \mathrm{L}$ of sample. This matrix was also tested adding ammonium citrate and ammonium acetate buffer $(10 \mu \mathrm{L}$ of matrix plus $3 \mu \mathrm{L}$ of buffer).

DCTB matrix (2-[(2E)-3-(4-tert-butylphenyl)-2-methylprop-2enylidene]malononitrile) was prepared in acetonitrile (ACN) and $\mathrm{ACN} /(\mathrm{TFA}, 0.1 \%)$ at $5 \mathrm{mg} / \mathrm{mL}$.

SA matrix (sinapic acid) was prepared using two different procedures: double layer (DL) and thin layer (TL). Double layer consists in applying a first layer (S1) of SA $(10 \mathrm{mg} / \mathrm{mL}$ in ethanol) onto the stainless steel target plate (MTP 394 target plate ground steel BC, Bruker Daltonics, Germany) and then applying a second layer (S2), which contains the sample. S2 consists of $2 \mu \mathrm{L}$ of SA at $10 \mathrm{mg} / \mathrm{mL}$ ACN:TFA (0.1\%) 30:70 overlaid with $2 \mu \mathrm{L}$ of the sample. Thin layer protocol consists in applying $2 \mu \mathrm{L}$ of sample onto the target plate, overlaid with $2 \mu \mathrm{L}$ of SA (10 mg/mL in ACN: TFA (0.1\%) 30:70). Samples were spotted in triplicate.

trans-3-Indoleacrylic acid (tIAA) and 2,5,-Dihydroxybenzoic acid (DHB) were also tested following the Bruker Daltonics recommendations. These matrices are appropriate and commonly used to high molecular weight proteins analysis.

Mass spectra were automatically acquired on an UltrafleXtream MALDI-TOF/TOF mass spectrometer (Bruker Daltonics, Germany) operating in linear positive ion detection mode with laser SmartBeamIII and under FlexCompass 1.4 software control (Bruker Daltonics, Germany). For each sample, the mass spectra (range from 2 to $30 \mathrm{kDa}$ ) of 1500 laser shots were accumulated with $2000 \mathrm{~Hz}$ of frequency.

2.4. FIA-ESI-MS Analysis. One milligram per milliliter of isolated acidic PRP fraction was diluted in Milli-Q water (1:1, 1:10 and 1:100) and analyzed before and after the interaction with malvidin 3-glucoside $(0.5$ and $1 \mathrm{mg} / \mathrm{mL} ; \mathrm{pH} 3.8)$. For the experiments, $50 \mu \mathrm{L}$ of anthocyanins solutions were added to $150 \mu \mathrm{L}$ of isolated PRP. Samples were vortexed, maintained for $30 \mathrm{~min}$ at room temperature, and then injected by flow injection analysis at $5 \mu \mathrm{L} / \mathrm{min}$ (FIA) into an LTQ Orbitrap XL mass spectrometer (Thermo Fischer Scientific, Bremen, Germany) controlled by LTQ Tune Plus 2.5.5 and Xcalibur 2.1.0. The capillary voltage of the electrospray ionization (ESI) was set to $3.1 \mathrm{kV}$. The capillary temperature was $275^{\circ} \mathrm{C}$. The sheath gas flow rate (nitrogen) was set to 5 (arbitrary unit as provided by the software seetings). The capillary voltage was $36 \mathrm{~V}$, and the tube lens voltage was $110 \mathrm{~V}$. Xcalibur 2.2 software was used to control the analysis and to interpret the data obtained. Proteins acquire different charge states in the interface so mass spectra were subjected to a deconvolution process using the charge ratio analysis method (CRAM) by MagTran 1.03 software.

Python is a bioinformatic tool with a scripting language very suitable for rapidly explore mass spectrometry data. ${ }^{24}$ It was employed to identify salivary protein soluble aggregates. Salivary protein ions adducts such as $\mathrm{K}^{+}$were considered, and several aggregate identifications were hypothesized.

2.5. Saturation-Transfer Difference NMR Spectroscopy. $0.1 \mathrm{mg}$ of lyophilized aPRPs was dissolved in $1 \mathrm{~mL}$ of $\mathrm{D}_{2} \mathrm{O}(99.9 \%)$ with $7 \%$ of dimethyl sulfoxide- $d_{6}(99.8 \%)$. Several aliquots of $100 \mu \mathrm{L}$ malvidin 3-glucoside $(1 \mathrm{mg} / \mathrm{mL})$ were lyophilized and successively dissolved by the same milliliter that contains the protein up to reach the desired pigment concentration. The selection of anthocyanin concentration was restricted essentially by the detection limit in the STD experiment. Prior to titration experiments and after each addition of anthocyanin, the $\mathrm{pH}$ was adjusted to 3.4 and $\mathrm{pH} 1.0$ by the addition of $\mathrm{DCl}(99.5 \%)$, in order to evaluate the hemiketal ( $\mathrm{pH} 3.4)$ and flavylium ( $\mathrm{pH}$ 1.0) forms of the anthocyanin.

$\mathrm{pH}$ measurements were made in a pH-meter WTW pH 320 fitted with a standard glass Crison 5209 electrode. The calibration was made with standard aqueous buffers at $\mathrm{pH} 4.0$ and $\mathrm{pH} 1.0$ from Crison. To obtain the conventional $\mathrm{pD}$ scale from glass electrode readings, the following equation was used:

$$
\mathrm{pD}=\mathrm{pH} \text { meter reading* }+0.4
$$

${ }^{*} \mathrm{pH}$ meter reading for solutions in $\mathrm{D}_{2} \mathrm{O}$ instead of $\mathrm{H}_{2} \mathrm{O}$ when the $\mathrm{pH}$ electrodes are calibrated with standard aqueous buffers.

STD effect was determined using the amplification factor $\left(A_{\mathrm{STD}}\right)$ according to the following equation: ${ }^{25}$

$$
A_{\mathrm{STD}}=\frac{I_{0}-I_{\mathrm{SAT}}}{I_{0}} \times \frac{[\mathrm{L}]}{[\mathrm{P}]}=\frac{I_{\mathrm{STD}}}{I_{0}} \times \frac{[\mathrm{L}]}{[\mathrm{P}]}
$$

where $I_{\mathrm{SAT}}$ is the signal intensity of the selectively saturated protein spectrum (on-resonance), and $I_{0}$ is the signal intensity of the spectrum recorded without protein saturation (off-resonance). [L] is the concentration of the ligand, and in this case corresponds to the anthocyanin concentration, and $[\mathrm{P}]$ is the protein (aPRPs) concentration. The determination of the dissociation constant $\left(K_{\mathrm{D}}\right)$ was calculated according to eq 2 by nonlinear least-squares-fitting curve using the Solver utility of Microsoft Excel.

$$
A_{\mathrm{STD}}=\frac{\alpha \mathrm{STD}[\mathrm{L}]}{K_{\mathrm{D}}+[\mathrm{L}]}
$$

where $\alpha \mathrm{STD}$ is the maximum amplification factor.

NMR experiments were recorded on a Bruker Avance III $600 \mathrm{HD}$ spectrometer, operating at $600.13 \mathrm{MHz}$, equipped with a $5 \mathrm{~mm}$ PATXI $1 \mathrm{H} / \mathrm{D}-13 \mathrm{C} / 15 \mathrm{~N}$ and pulse gradient units capable of producing magnetic field pulsed gradients in the $z$ direction of $50 \mathrm{G} / \mathrm{cm}$. The measurements were made with standard Bruker pulse sequences at $300 \mathrm{~K} .{ }^{1} \mathrm{H}$ and STD spectra were recorded with a shaped pulse to suppress the water resonance using the following parameters: spectral width, $16 \mathrm{ppm}$; nutation angle, $7.08 \mu \mathrm{s}$ and $90^{\circ}$; and shaped pulse duration, 2 ms. Selective saturation of the peptide off-resonance at $20 \mathrm{ppm}$ and on-resonance at $-1 \mathrm{ppm}$ was performed using a pseudotwo-dimensional (2D) sequence for STD with a shaped pulse train alternating between the on and off resonances. ${ }^{26}$ STD-NMR spectra were acquired using Gaus 1.1000 pulses for selective saturation $(50 \mathrm{~ms})$, with a total saturation time of $2.5 \mathrm{~s}$. The number of scans (32), receptor 


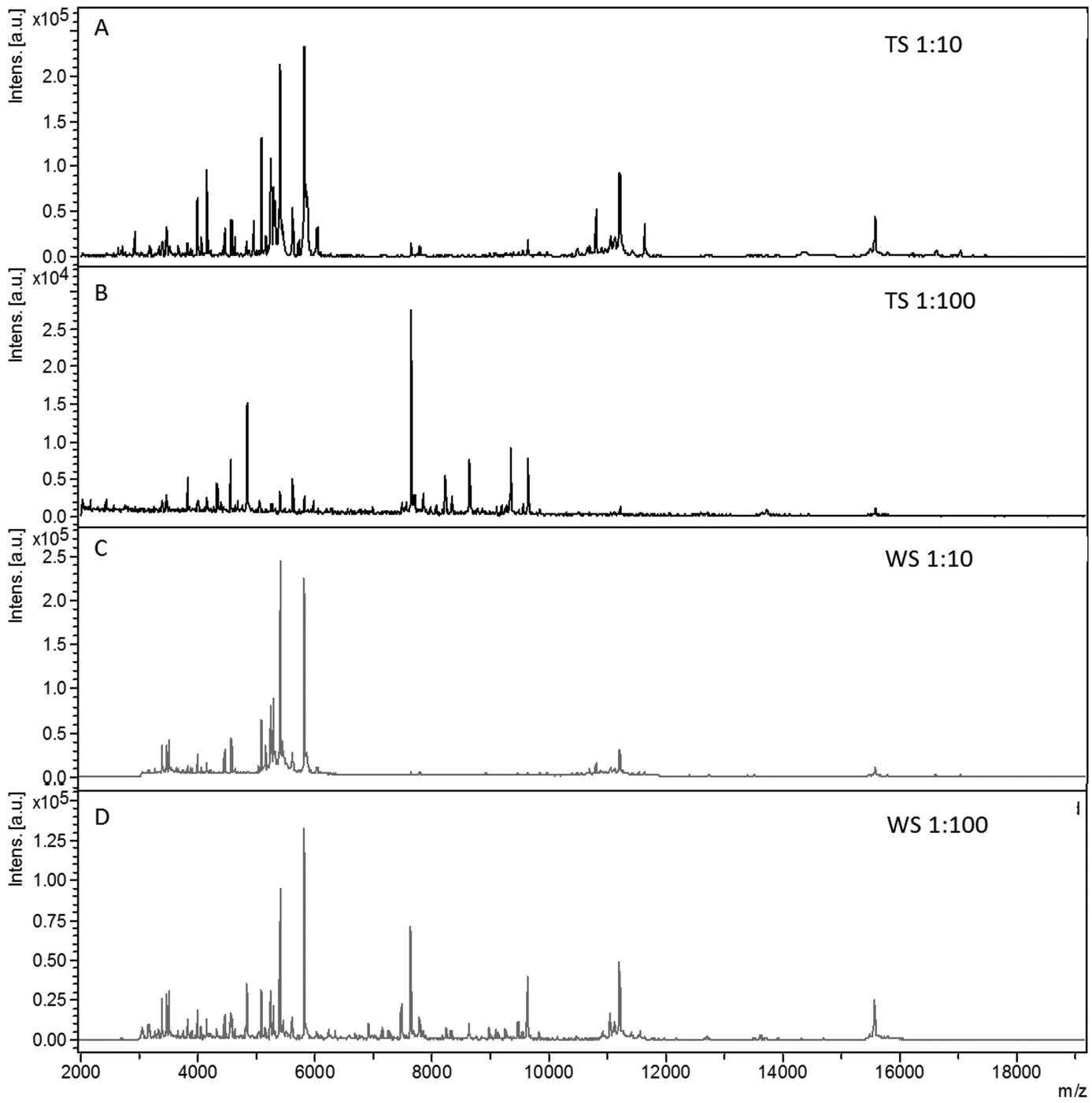

Figure 1. MALDI-TOF spectra differences between saliva centrifuged and treated with TFA (TS) and whole saliva (WS) nontreated and noncentrifuged at different dilution ratios (1:10 and 1:100).

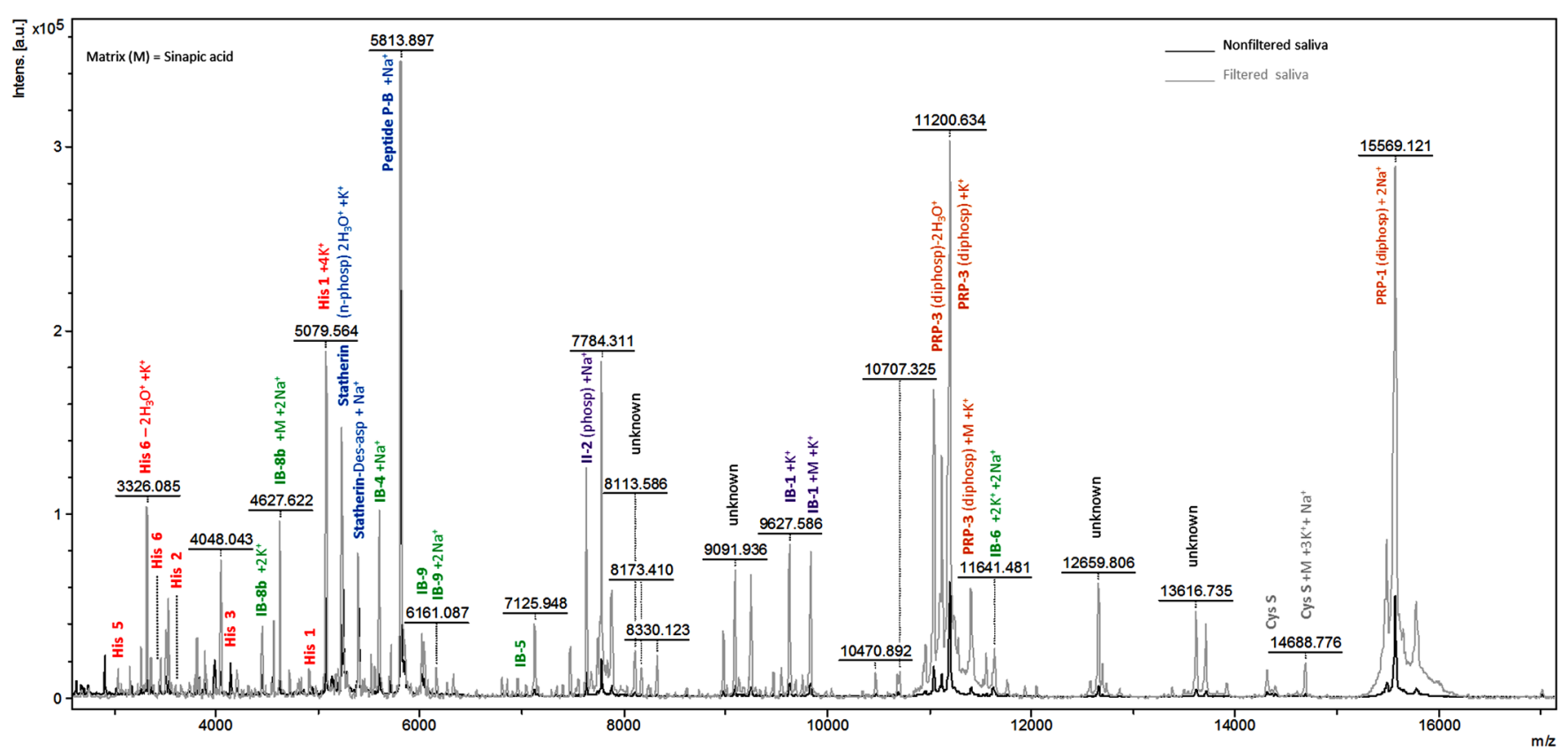

Figure 2. MALDI-TOF spectra of human salivary proteins of filtered and nonfiltered saliva samples. 


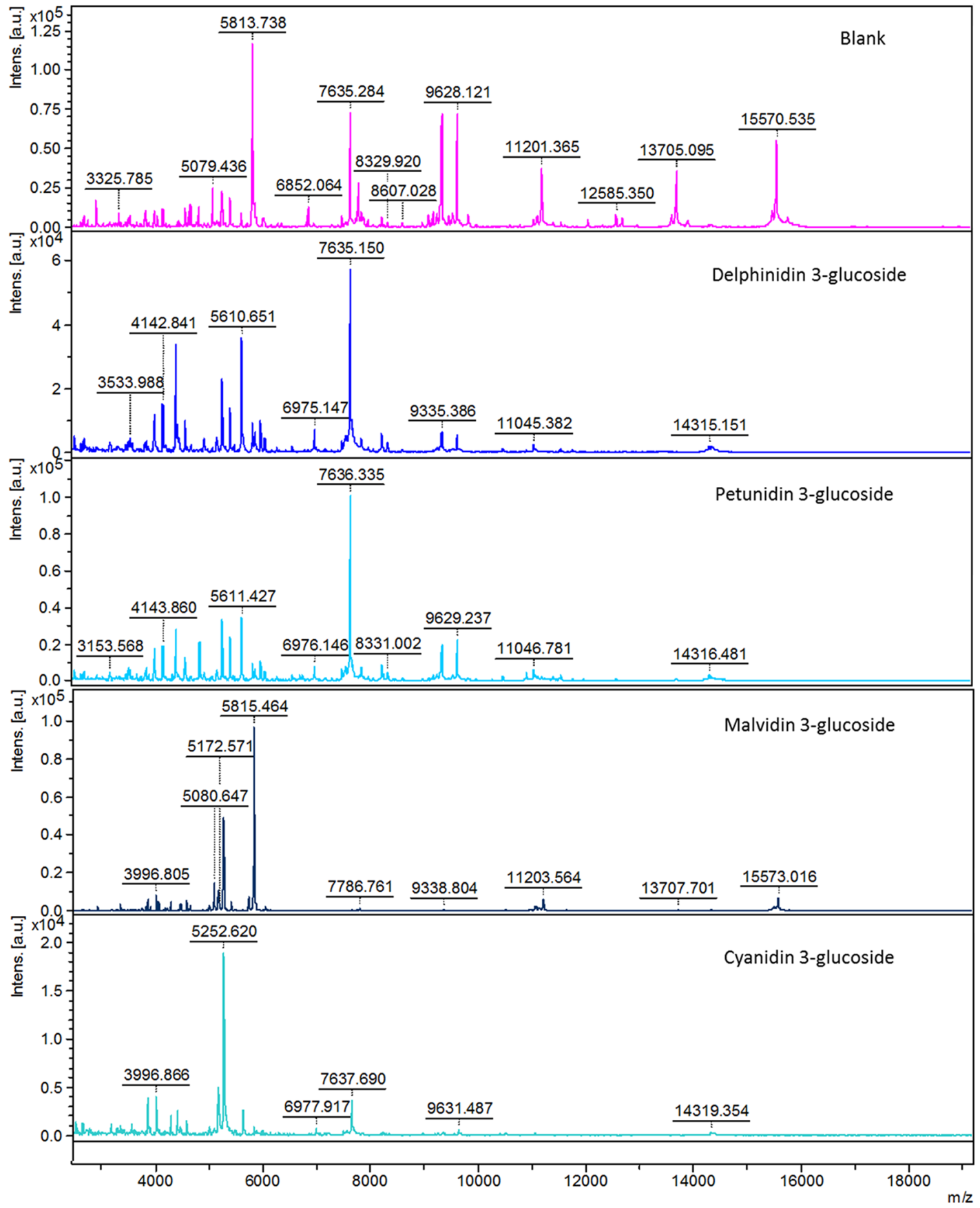

Figure 3. MALDI-TOF saliva (1:10) spectrum before and after the addition of anthocyanin 3-glucosides $(0.5 \mathrm{mg} / \mathrm{mL})$.

gain value (1440), and relaxation delay (3.5 s) were kept constant. To subtract the unprocessed on and off-resonance spectra, to baseline correct the resulting difference spectrum, and to integrate the areas, TopSpin 2.1 software from Bruker was used.

2.6. Sensory Analysis. A mixture of anthocyanins with a chromatographic profile similar to that of red wine was used for the sensory analysis using a professionally trained sensory panel. ${ }^{27}$ Panelists were not informed about the identity of the samples and not paid. A labeled magnitude scale from 0 to 100 (Supporting Information Figure SI-1) were used. ${ }^{28}$ Intensity of astringency, bitterness, velvety, dryness, harshness, unripe, dynamics, and persistence were evaluated.

\section{RESULTS AND DISCUSSION}

3.1. Analysis of Human Saliva Profile by MALDI-TOF-

MS. In order to optimize the analysis of the profile of the human salivary proteins, different matrices and sample procedures were assessed. Five matrices (DHAP, DHB, tIAA, DCTB, and SA) were used at different preparation protocols as explained above. Thin layer preparation mode of sinapic acid (SA) showed the best signal intensity, resolution, and sensitivity at the studied mass range (from 2 to $30 \mathrm{kDa}$ ) and was hence used to carry out the experiments. SA is a commonly used matrix in human saliva peptide analysis by MALDI-TOF-MS. ${ }^{5}$

In Figure 1 we can observe the MALDI-TOF spectral differences between TS (saliva centrifuged and treated with trifluoroacetic acid (TFA)) and WS (whole saliva; nontreated and noncentrifuged). Figure 1 also shows the differences between saliva samples diluted with water 1:10 (Figure 1A,C) and 1:100 (Figure 1B,D). The majority of signals at 1:10 dilution ratio were 


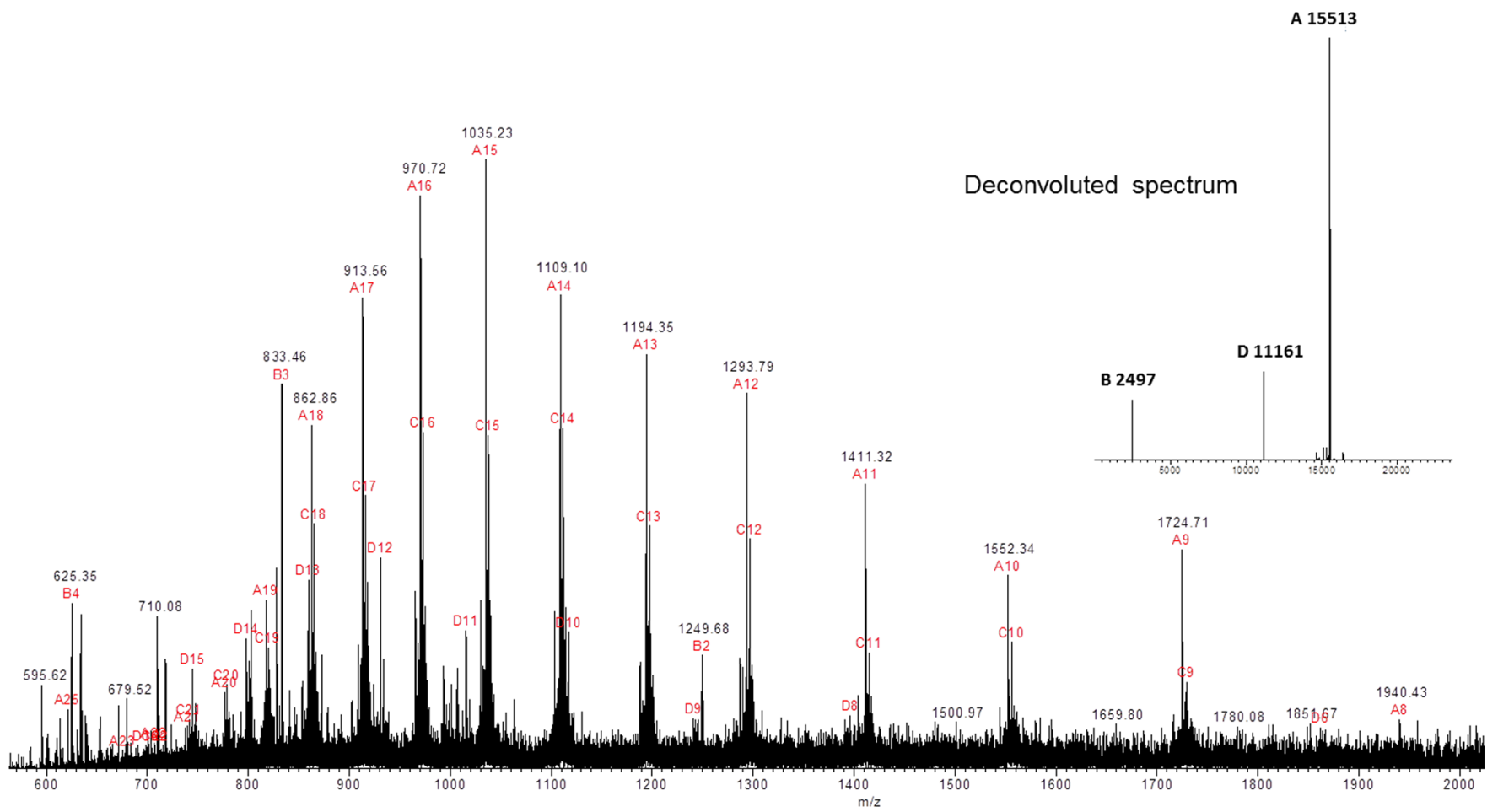

Figure 4. ESI-FIA-MS spectrum of the isolated saliva fraction and the corresponding MagTran deconvolution spectrum.

embedded in the $m / z 3000-6000$ Da range. For this dilution, TS spectra showed higher number of peaks than WS at this range, and also several differences in the signal intensity around 9000 and $15000 \mathrm{Da}$ were observed. The ionization of the saliva proteins with molecular weight rounding 6 and $11 \mathrm{kDa}$ was favored when the saliva was diluted 100 times. In this case (Figure 1B), the increase of the proteins intensity embedded in the $6-11 \mathrm{kDa}$ range for the treated and diluted saliva seems to be associated with a decrease in the lower molecular weight proteins (from 5 to $6 \mathrm{kDa}$ ).

When saliva was diluted $1: 100$, WS displayed higher number of signals than TS and showed a suitable profile (Figure 1D) to determine a high number of peptides. It should be highlighted that the WS samples were quickly prepared as saliva was spit out, diluted and immediately put onto the target plate. The estimated time of sample preparation and analysis is around 10-15 min. This procedure could be a valuable tool in the identifcation of potential biomarkers in biomedical studies involving saliva. $^{29}$

In order to improve the MALDI-TOF profile, saliva was filtered and compared with nonfiltered saliva (Figure 2). In general, filtration improves MALDI-TOF-MS salivary peptide analysis. ${ }^{30}$ Here, it can be observed that filtered saliva samples spectra showed higher number of peaks, higher intensities, and better resolution signals.

Salivary proteins were identified according to the molecular masses previously reported. ${ }^{23,31}$ Histatins (1, 2, 3, 5 and 6), statherins (sthaterin nonphosphorylated, sthaterin-Des-asp and $\mathrm{P}-\mathrm{B}$ peptide), basic PRPs (IB-4, IB-5, IB-6, IB-8b, IB-9), glycosylated PRPs (II-2 phosphorylated and IB-1), acidic PRPs (PRP1-diphosphorylated, PRP3-diphosphorylated), cystatins, and some unknown proteins (8113, 9091, 12659, and 13626 $\mathrm{m} / z$ ) were found. Some matrix adducts with sodium $[\mathrm{M}+\mathrm{Na}]^{+}$ and/or potassium $[\mathrm{M}+\mathrm{K}]^{+}$as well as the loss of water $\left[\mathrm{M}-\mathrm{H}_{3} \mathrm{O}\right]^{+}$ were also found in the analysis.
In general, differences in the ionization ability of the salivary proteins are strongly linked to the matrix and procedure (treatment and dilution). Filtration seems to be a suitable approach for the saliva peptide determination by MALDI-TOFMS. Here, filtration of TS resulted in the best salivary protein profile with the highest number and intensity of peaks, and also sensitivity and resolution. Therefore, this procedure was used to carry out the saliva-anthocyanins interaction assessments.

3.2. Anthocyanin-Human Saliva Interactions by MALDI-TOF-MS. Some experiments were carried out in order to gain insights into the interactions between the saliva proteins and anthocyanins. For this, different concentrations ( 0.5 and $1 \mathrm{mg} / \mathrm{mL}$ ) of malvidin 3-glucoside, cyanidin 3-glucoside, petunidin 3-glucoside, and delphinidin 3-glucoside and saliva (nondiluted and diluted 10 and 100 times) were mixed and analyzed by MALDI-TOF-MS.

The addition of anthocyanins largely changes the saliva protein profile spectra (Figure 3). In general, at low weight molecular masses (from 2000 to $6000 \mathrm{Da}$ ) some signals observed in the blank disappeared, while new signals emerged. This is the case of the signal 5813 in the blank and the signals 5610 and 5611 in the samples of delphinidin 3-glucoside and petunidin 3-glucoside, respectively. Some of these new peaks were present in experiments with different anthocyanins, meaning that they not do concern new soluble anthocyanin-saliva aggregates since they appeared independently of the anthocyanin added. Moreover, some of the emerging peaks that appeared in the samples with anthocyanin correspond to the small signals shown in the blank; this is the case of the mentioned signals (5610 and 5611).

Regarding the highest molecular weight proteins (from 9 to $20000 \mathrm{Da}$ ), the majority of signals tend to disappear after the addition of anthocyanins, mainly corresponding to the acidic proline-rich proteins (PRP3 and PRP1). This behavior suggests the interaction between the human salivary proteins and anthocyanins and may be explained by the formation of large 

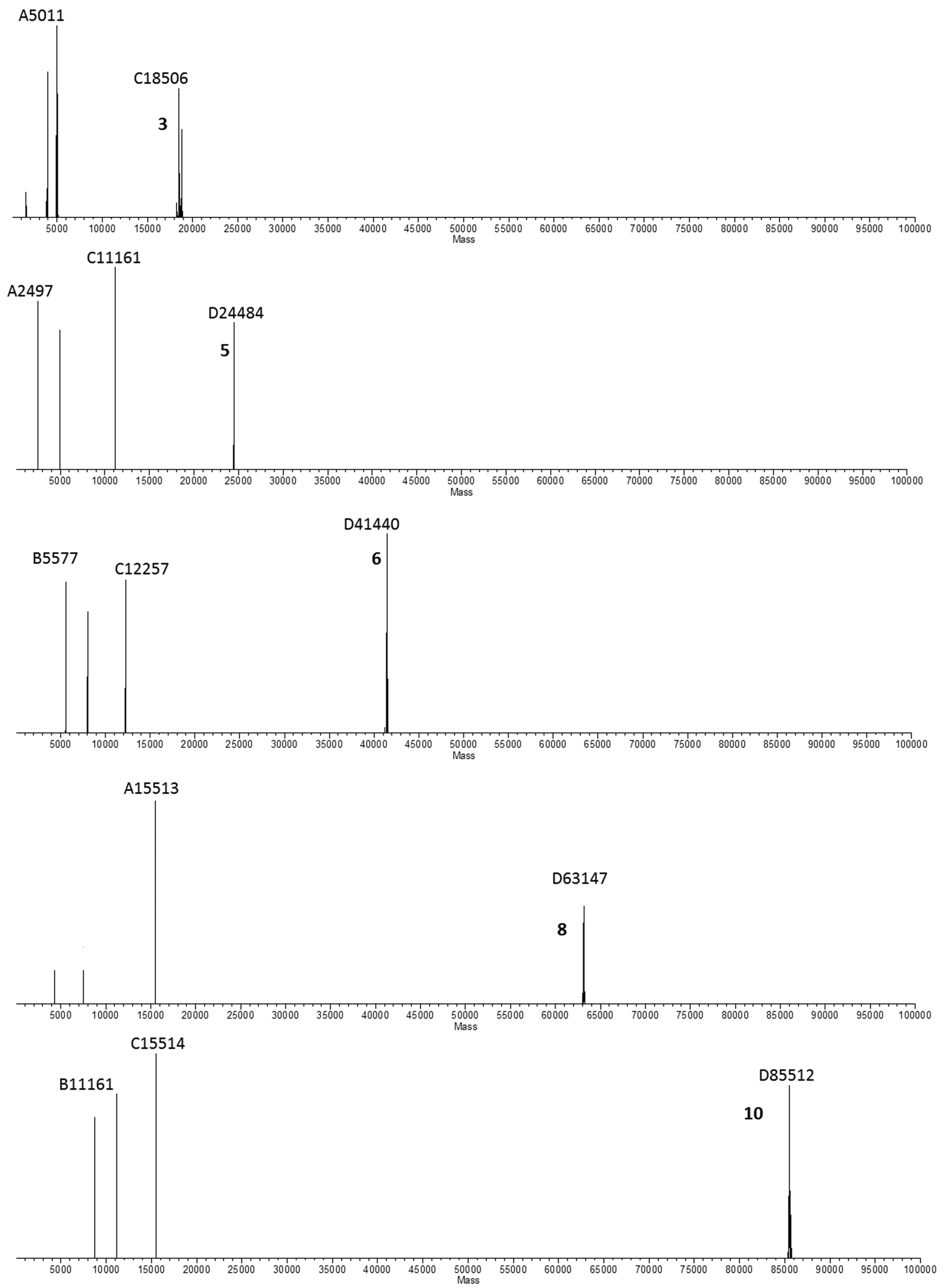

Figure 5. MagTran deconvolution spectra of some of the new anthocyanin/human saliva proteins complexes shown in Table 1 (complexes 3, 5, 6, 8 , and 10). 
colloidal complexes and the resulting precipitation. Nevertheless visual precipitation was not observed. On the other hand, the formation of soluble aggregates with higher molecular masses than 20000 Da could have occurred. However, the complexity of the saliva samples and the slight ionization of this technique make their determination difficult. MALDI-TOF-MS sensitivity decreases for higher molecular masses, and FIA-ESI-MS has been stated as the most suitable technique to evaluate large tanninsalivary protein aggregates. ${ }^{14,32}$

3.3. New Malvidin 3-Glucoside-Saliva Protein Complexes by FIA-ESI-MS. In order to determine the possible formation of anthocyanin-salivary protein soluble aggregates, some experiments were carried out using malvidin 3-glucoside (the most common anthocyanin present in $V$. vinifera $L$. varieties) and an isolated fraction of saliva containing mainly acidic proline-rich proteins (see Methods and Materials), salivary proteins that interact first with tannins. ${ }^{23}$

Figure 4 shows the ESI-FIA-MS spectrum of the isolated fraction of aPRPs and the corresponding MagTran deconvolution spectrum. It can be observed that the saliva fraction used contains mainly acidic proline-rich proteins (aPRPs), namely PRP3 (diphosphorylated) and PRP1 (diphosphorylated) corresponding to the masses 15513 and 11161 , respectively. In this fraction, the peptide sequence $(33-51)$ of histatin was found (His), which corresponds to the mass 2497 of the spectrum.

Different ratios between malvidin 3-glucoside and aPRPs fraction were analyzed by ESI-FIA-MS. New peaks appeared suggesting the formation of new soluble aggregates between anthocyanins and the mentioned salivary proteins (Figure 5). Table 1 shows a putative identification of these new complexes. Up to 10 new soluble complexes between the malvidin 3-glucoside $(\mathrm{Mv})$, the peptide sequence of the Histatin 3 (His), and the proline-rich proteins PRP1 and PRP3 were identified.

The smallest complex observed corresponded to the mass 4963 (5 molecules of malvidin 3-glc and 1 molecule of Histatin 3). The highest complex observed corresponded to the mass 85512 and its putative identification corresponded to 2 molecules of malvidin, 4 molecules of PRP1, and 2 molecules of PRP3. The maximum number of malvidin molecules found in the complexes was 6 , and the maximum number of peptide molecules was 3 in the case of the histatin, 4 in the case of PRP1, and 3 in the case of PRP3.

3.4. Saturation-Transfer Difference NMR Spectroscopy. In order to quantify the interaction between malvidin 3-glc and aPRPs solution, the dissociation constant $\left(K_{\mathrm{D}}\right)$ was measured using STD NMR spectroscopy.

To confirm that the on-resonance irradiation frequency did not affect the anthocyanins' aromatic protons and that the protein was saturated by the on-resonance irradiation, some experiments were performed at high anthocyanin concentrations. For anthocyanin alone, in the difference STD spectrum the anthocyanins' aromatic resonances were not visible at the experimental conditions, which indicates that the on-resonance irradiation frequency does not overlap with these resonances.

The binding affinity between the isolated saliva fraction (aPRPs) and malvidin 3-glucoside was followed by measuring the intensities of malvidin 3-glc protons $\left(\mathrm{H}^{\prime}{ }^{\prime}\right.$ and $\mathrm{H}^{\prime}$ of the hemiketal form) at increasing concentrations. At $\mathrm{pH} 3.4$ the neutral hemiketal form of the anthocyanin (Figure 6) is expected to be the main equilibrium species present in solution and can be easily identified because of the existence of twin peaks. ${ }^{33,34}$ The assignment of the resonances due to the flavylium cation and chalcone forms was made according to the literature. ${ }^{35}$
Table 1. Putative Identification of New Soluble Aggregates between Malvidin 3-Glucoside (Mv), Histatin 3 (His) and the Proline-Rich Proteins (PRP1 and PRP3)

$\begin{array}{cccc}\begin{array}{c}\text { soluble } \\ \text { complex }\end{array} & \mathrm{MS}^{a} & \text { putative identification } & \text { abbreviated } \\ \text { identification }\end{array}$

${ }^{a}$ Experimental mass obtained by MagTran deconvolution from ESI-MS spectra.

The STD amplification factor was calculated from the differences between off-ressonance and on-ressonance spectra with increasing anthocyanin concentration, according to eq 1 . To consider the effect of the self-association phenomena in the anthocyanins equilibrium (Figure 6), the signal intensities of $\mathrm{H} 2^{\prime}$ and $\mathrm{H}^{\prime}$ of hemiketal form were corrected, at each concentration, in relation to the intensities of the $\mathrm{AH}^{+}, \mathbf{C c}$, and $\mathbf{C t}$ forms. Thus, at the initial concentration of malvidin 3-glucoside $(1.3 \mathrm{mM})$ only $76 \%$ of the anthocyanin was in the $\mathbf{B}$ form, which corresponds to a real concentration of $1.0 \mathrm{mM}$ (Figure 7A,B). In these conditions, $8 \%$ corresponds to the $\mathrm{AH}^{+}$form, $4 \%$ to the Ct form and $11 \%$ to the Cc form. Due to the self-association effect, at higher concentrations of malvidin 3-glucoside, the chemical equilibrium toward $\mathrm{AH}^{+}$became increasingly pronounced, which resulted in lower differences in the $\mathbf{B}$ form real concentration (last 3 experimental points, Figure 7B). At the concentrations studied, percentages of flavylium cation amount were ranged from 8 to $12 \%$. This increase in the $\mathrm{AH}^{+}$form involved a decrease in the amount of the $\mathbf{B}$ form (from 76 to $71 \%)$.

The dissociation constant in the interaction between malvidin 3-glucoside and acidic PRPs for the different forms of the anthocyanin was calculated according to eq 2 using the Solver tool of the Microsof Excel software. Figure 7 shows the observed (symbols) and fitted (line) STD amplification factor of malvidin 3-glucoside at $\mathrm{pH} 3.4$ (A and B) and $\mathrm{pH} 1$ (C). As stated above, the effect of the self-association phenomena in the anthocyanins equilibrium was considered at $\mathrm{pH} 3.4$ (Figure 7B). Thus, the corrected $K_{\mathrm{D}}$ obtained for the hemiketal form was $1.92 \mathrm{mM}$ with a confidence level of $88.9 \%$. At $\mathrm{pH} 1$, the obtained $K_{\mathrm{D}}$ for the flavylium cation was $1.83 \mathrm{mM}$ (Figure 7C) with a confidence level of $85.7 \%$. Dissociation constants ranging from 0.4 to $8 \mathrm{mM}$ for the interaction between the human saliva proline-rich peptides (IB7 ${ }_{14}$ and IB9 $9_{37}$ ) and procyanidins were shown by other authors. ${ }^{18,36}$ Recently, it has been stated that polymeric proanthocyanidins have much higher reactivity 

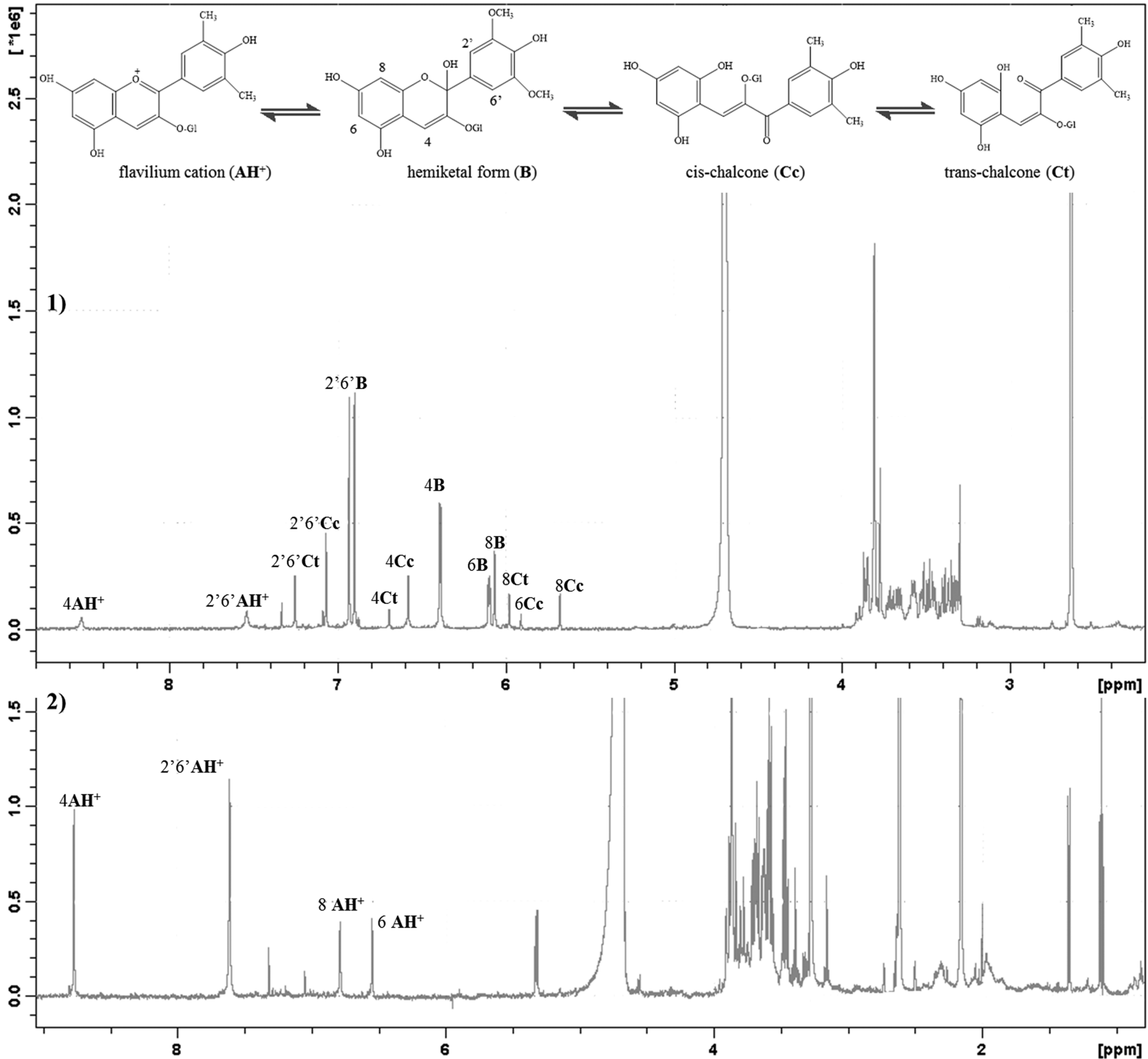

Figure 6. Equilibrium forms of the anthocyanins in acidic medium and ${ }^{1} \mathrm{H}$ spectra recorded in $\mathrm{D}_{2} \mathrm{O} / \mathrm{DMSO}$ (7\%) for a mixture of isolated saliva fraction (aPRPs) and malvidin 3-glucoside at $\mathrm{pH} 3.4(1)$ and at $\mathrm{pH} 1.0$ (2).

toward human salivary proteins than oligomeric ones ${ }^{37}$ and that the number of the hydroxyl substituents present in the B-ring of the flavanic nucleus is decisive for the interaction with human salivary proteins. ${ }^{38}$ The interaction between epigallocatechin gallate and the procyanidin dimers B2 and B2 $3^{\prime} \mathrm{O}$-gallate with the salivary proline-rich protein (IB5) was also evaluated showing the number of binding sites $(n=8)$ and that the protein undergo a structural rearrangement upon the binding. ${ }^{15,39,40}$ Recently, it has also been stated that the degree of polymerization and the galloylation do not modify the binding site on IB5 involved in the interaction. ${ }^{41}$

Besides the anthocyanin equilibrium form, differences in the charge distribution and conformation of the protein at the studied $\mathrm{pH}$ should also be taken into account in the binding affinity. This dependence on both anthocyanin and protein features may explain the similar behavior of the obtained dissociation constants.
3.5. Sensory Analysis. Figure SI-1 in the Supporting Information shows the subqualities of the astringency and bitterness of anthocyanins in wine. Sensory tests were carried out in a white wine previously dearomatized under vacuum. This wine was selected for its absence of astringency. Slight subqualities of astringency and bitterness of anthocyanins were observed in the solution containing $80 \mathrm{mg} / \mathrm{L}$. When the anthocyanin concentration was raised from $80 \mathrm{mg} / \mathrm{L}$ to $400 \mathrm{mg} / \mathrm{L}$, small changes were observed: a very small increase in the intensity of astringency and a minor sensation of ripeness were perceived. These results suggested a really slight sensation of astringency elicited by glucosylated anthocyanins, which is in good agreement with the results of other authors. ${ }^{1}$

\section{CONCLUSIONS}

Anthocyanins were able to interact with human salivary proteins. The strength of the interaction between malvidin 3-glucoside 

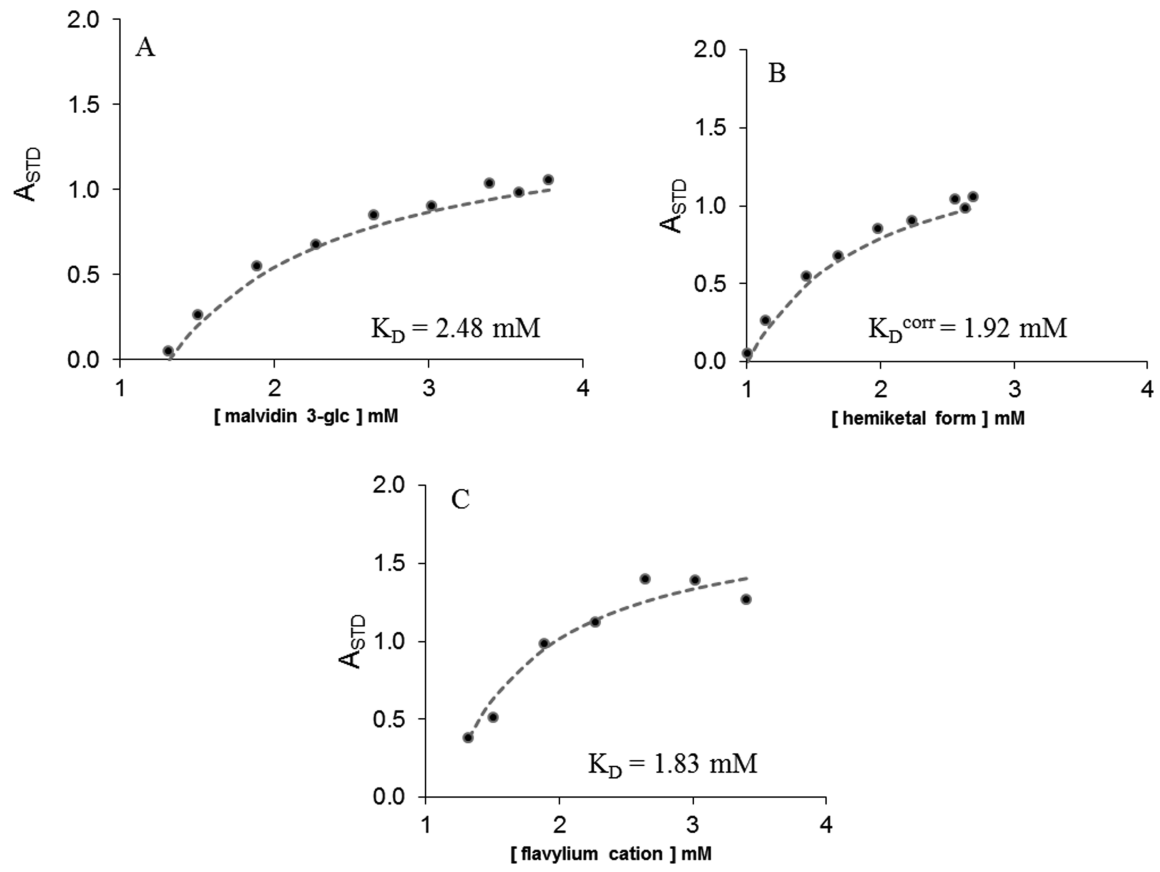

Figure 7. STD amplification factor of malvidin 3-glucoside at $\mathrm{pH} 3.4$ (A and $\mathrm{B}$ ) and $\mathrm{pH} 1$ (C) and the corresponding dissociation constants. Symbols represent experimental values, and lines represent calculated values by eq 2 .

and the acidic proline-rich proteins (aPRPs) was characterized by STD NMR spectroscopy. The dissociation constant of the anthocyanin in the hemiketal form ( $\mathrm{pH} 3.4)$ and in the flavylium form ( $\mathrm{pH}$ 1.0) was obtained, revealing similar affinity for these proteins. New complexes between malvidin 3-glucoside, prolinerich proteins, and histatins have been identified for the first time. This study suggests that the interaction between anthocyanins and salivary proteins leads to soluble aggregates that barely induce astringency perception. However, it can be envisaged that this interaction may indirectly affect the development of the astringency of fruits and derived products, such as red wine, by hindering the interaction between the proteins and other flavonoids such as proanthocyanins, well-known elicitors of astringency. This paper opens up new avenues for discussion about the contribution of the salivary complexes to the astringency global perception.

For future experiments, it would also be interesting to evaluate the importance of this interaction from a nutritional point of view.

\section{ASSOCIATED CONTENT}

\section{S Supporting Information}

Figure showing the subqualities of the astringency and bitterness of anthocyanins in wine. The Supporting Information is available free of charge on the ACS Publications website at DOI: 10.1021 /acs.langmuir.5b01122.

\section{AUTHOR INFORMATION}

\section{Corresponding Author}

*Phone: +351 220402 000; Fax: +351 220402 00; E-mail: rauferga@usal.es.

\section{Notes}

The authors declare no competing financial interest.

\section{ACKNOWLEDGMENTS}

Thanks are due to the Spanish MICINN (Project ref AGL2011-30254-C02-01 and AGL2014-58486-C2-1-R) and the research project grant (NORTE-07-0162-FEDER-000048) and UID/QUI/50006/2013 for financial support. R. FerrerGallego thanks Fundación Alfonso Martín Escudero for the postdoctoral fellowship.

\section{REFERENCES}

(1) Vidal, S.; Francis, L.; Noble, A.; Kwiatkowski, M.; Cheynier, V.; Waters, E. Taste and mouth-feel properties of different types of tanninlike polyphenolic compounds and anthocyanins in wine. Anal. Chim. Acta 2004, 513, 57-65.

(2) Soares, S.; Kohl, S.; Thalmann, S.; Mateus, N.; Meyerhof, W.; De Freitas, V. Different Phenolic Compounds Activate Distinct Human Bitter Taste Receptors. J. Agric. Food Chem. 2013, 61, 1525-1533.

(3) de Freitas, V.; Mateus, N. Protein/Polyphenol Interactions: Past and Present Contributions. Mechanisms of Astringency Perception. Curr. Org. Chem. 2012, 16, 724-746.

(4) Scollary, G. R.; Pasti, G.; Kallay, M.; Blackman, J.; Clark, A. C. Astringency response of red wines: Potential role of molecular assembly. Trends Food Sci. Technol. 2012, 27, 25-36.

(5) Perez-Gregorio, M. R.; Mateus, N.; de Freitas, V. Rapid Screening and Identification of New Soluble Tannin-Salivary Protein Aggregates in Saliva by Mass Spectrometry (MALDI-TOF-TOF and FIA-ESIMS). Langmuir 2014, 30, 8528-8537.

(6) Pascal, C.; Poncet-Legrand, C.; Cabane, B.; Vernhet, A. Aggregation of a proline-rich protein induced by epigallocatechin gallate and condensed tannins: Effect of protein glycosylation. J. Agric. Food Chem. 2008, 56, 6724-6732.

(7) Jobstl, E.; O’Connell, J.; Fairclough, J. P. A.; Williamson, M. P. Molecular model for astringency produced by polyphenol/protein interactions. Biomacromolecules 2004, 5, 942-949.

(8) Obreque-Slier, E.; López-Solís, R.; Peña-Neira, Á.; ZamoraMarín, F. Tannin-protein interaction is more closely associated with astringency than tannin-protein precipitation: experience with two oenological tannins and a gelatin. Int. J. Food Sci. Technol. 2010, 45, 2629-2636.

(9) Ma, W.; Guo, A.; Zhang, Y.; Wang, H.; Liu, Y.; Li, H. A review on astringency and bitterness perception of tannins in wine. Trends Food Sci. Technol. 2014, 40, 6-19.

(10) Humphrey, S. P.; Williamson, R. T. A review of saliva: Normal composition, flow, and function. J. Prosthet. Dent. 2001, 85, 162-169. 
(11) de Sousa-Pereira, P.; Amado, F.; Abrantes, J.; Ferreira, R.; Esteves, P. J.; Vitorino, R. An evolutionary perspective of mammal salivary peptide families: Cystatins, histatins, statherin and PRPs. Arch. Oral Biol. 2013, 58, 451-458.

(12) Messana, I.; Inzitari, R.; Fanali, C.; Cabras, T.; Castagnola, M. Facts and artifacts in proteomics of body fluids. What proteomics of saliva is telling us? J. Sep. Sci. 2008, 31, 1948-1963.

(13) Bennick, A. Salivary Proline-Rich Proteins. Mol. Cell. Biochem. 1982, 45, 83-99.

(14) Canon, F.; Pate, F.; Meudec, E.; Marlin, T.; Cheynier, V.; Giuliani, A.; Sarni-Manchado, P. Characterization, stoichiometry, and stability of salivary protein-tannin complexes by ESI-MS and ESI-MS/ MS. Anal. Bioanal. Chem. 2009, 395, 2535-2545.

(15) Canon, F.; Pate, F.; Cheynier, V.; Sarni-Manchado, P.; Giuliani, A.; Perez, J.; Durand, D.; Li, J.; Cabane, B. Aggregation of the Salivary Proline-Rich Protein IB5 in the Presence of the Tannin EgCG. Langmuir 2013, 29, 1926-1937.

(16) Sarni-Manchado, P.; Cheynier, V. Study of non-covalent complexation between catechin derivatives and peptides by electrospray ionization mass spectrometry. J. Mass Spectrom. 2002, 37, 609616.

(17) Cala, O.; Fabre, S.; Pinaud, N.; Dufourc, E. J.; Fouquet, E.; Laguerre, M.; Pianet, I. Towards a Molecular Interpretation of Astringency: Synthesis, 3D Structure, Colloidal State, and Human Saliva Protein Recognition of Procyanidins. Planta Med. 2011, 77, $1116-1122$.

(18) Cala, O.; Dufourc, E. J.; Fouquet, E.; Manigand, C.; Laguerre, M.; Pianet, I. The Colloidal State of Tannins Impacts the Nature of Their Interaction with Proteins: The Case of Salivary Proline-Rich Protein/Procyanidins Binding. Langmuir 2012, 28, 17410-17418.

(19) Sarni-Manchado, P.; Canals-Bosch, J.-M.; Mazerolles, G.; Cheynier, V. Influence of the Glycosylation of Human Salivary Proline-Rich Proteins on Their Interactions with Condensed Tannins. J. Agric. Food Chem. 2008, 56, 9563-9569.

(20) Vidal, S.; Francis, L.; Guyot, S.; Marnet, N.; Kwiatkowski, M.; Gawel, R.; Cheynier, V.; Waters, E. J. The mouth-feel properties of grape and apple proanthocyanidins in a wine-like medium. J. Sci. Food Agric. 2003, 83, 564-573.

(21) Yao, J.-W.; Lin, F.; Tao, T.; Lin, C.-J. Affinity interactions between natural pigments and human whole saliva. Arch. Oral Biol. 2011, 56, 285-293.

(22) Brandao, E.; Soares, S.; Mateus, N.; de Freitas, V. Human saliva protein profile: Influence of food ingestion. Food Res. Int. 2014, 64, 508-513.

(23) Soares, S.; Vitorino, R.; Osorio, H.; Fernandes, A.; Venancio, A.; Mateus, N.; Amado, F.; de Freitas, V. Reactivity of Human Salivary Proteins Families Toward Food Polyphenols. J. Agric. Food Chem. 2011, 59, 5535-5547.

(24) Bald, T.; Barth, J.; Niehues, A.; Specht, M.; Hippler, M.; Fufezan, C. pymzML-Python module for high-throughput bioinformatics on mass spectrometry data. Bioinformatics 2012, 28, 10521053.

(25) Viegas, A.; Manso, J.; Nobrega, F. L.; Cabrita, E. J. SaturationTransfer Difference (STD) NMR: A Simple and Fast Method for Ligand Screening and Characterization of Protein Binding. J. Chem. Educ. 2011, 88, 990-994.

(26) Goncalves, R; Mateus, N.; Pianet, I.; Laguerre, M.; de Freitas, V. Mechanisms of Tannin-Induced Trypsin Inhibition: A Molecular Approach. Langmuir 2011, 27, 13122-13129.

(27) Ferrer-Gallego, R.; Hernández-Hierro, J. M.; Rivas-Gonzalo, J. C.; Escribano-Bailón, M. T. Sensory evaluation of bitterness and astringency sub-qualities of wine phenolic compounds: synergistic effect and modulation by aromas. Food Res. Int. 2014, 62, 1100-1107.

(28) Green, B. G.; Dalton, P.; Cowart, B.; Shaffer, G.; Rankin, K.; Higgins, J. Evaluating the 'labeled magnitude scale' for measuring sensations of taste and smell. Chem. Senses 1996, 21, 323-334.

(29) Chaiyarit, P.; Taweechaisupapong, S.; Jaresitthikunchai, J.; Phaonakrop, N.; Roytrakul, S. Comparative evaluation of $5-15-\mathrm{kDa}$ salivary proteins from patients with different oral diseases by MALDITOF/TOF mass spectrometry. Clin. Oral Investig. 2015, 19, 729-737.

(30) Vitorino, R.; Barros, A. S.; Caseiro, A.; Ferreira, R.; Amado, F. Evaluation of different extraction procedures for salivary peptide analysis. Talanta 2012, 94, 209-215.

(31) Vitorino, R.; Barros, A.; Caseiro, A.; Domingues, P.; Duarte, J.; Amado, F. Towards defining the whole salivary peptidome. Proteomics: Clin. Appl. 2009, 3, 528-540.

(32) Perez-Gregorio, M. R.; Mateus, N.; De Freitas, V. New Procyanidin B3-Human Salivary Protein Complexes by Mass Spectrometry. Effect of Salivary Protein Profile, Tannin Concentration, and Time Stability. J. Agric. Food Chem. 2014, 62, 1003810045 .

(33) Leydet, Y.; Gavara, R.; Petrov, V.; Diniz, A. M.; Jorge Parola, A.; Lima, J. C.; Pina, F. The effect of self-aggregation on the determination of the kinetic and thermodynamic constants of the network of chemical reactions in 3-glucoside anthocyanins. Phytochemistry 2012, 83, 125-135.

(34) Fernandes, A.; Bras, N. F.; Mateus, N.; de Freitas, V. Understanding the Molecular Mechanism of Anthocyanin Binding to Pectin. Langmuir 2014, 30, 8516-8527.

(35) Santos, H.; Turner, D. L.; Lima, J. C.; Figueiredo, P.; Pina, F. S.; Macanita, A. L. Elucidation of the Multiple Equilibria of Malvidin in Aqueous Solution by One- And Two Dimensional NMR. Phytochemistry 1993, 33, 1227-1232.

(36) Cala, O.; Pinaud, N.; Simon, C.; Fouquet, E.; Laguerre, M.; Dufourc, E. J.; Pianet, I. NMR and molecular modeling of wine tannins binding to saliva proteins: revisiting astringency from molecular and colloidal prospects. FASEB J. 2010, 24, 4281-4290.

(37) Sun, B.; de Sa, M.; Leandro, C.; Caldeira, I.; Duarte, F. L.; Spranger, I. Reactivity of Polymeric Proanthocyanidins toward Salivary Proteins and Their Contribution to Young Red Wine Astringency. J. Agric. Food Chem. 2013, 61, 939-946.

(38) Ferrer-Gallego, R.; Quijada-Morín, N.; Brás, N. F.; Gomes, P.; de Freitas, V.; Rivas-Gonzalo, J. C.; Escribano-Bailón, M. T. Characterization of Sensory Properties of Flavanols-A Molecular Dynamic Approach. Chem. Senses 2015, 40, 381-390.

(39) Canon, F.; Giuliani, A.; Paté, F.; Sarni-Manchado, P. Ability of a salivary intrinsically unstructured protein to bind different tannin targets revealed by mass spectrometry. Anal. Bioanal. Chem. 2010, 398, $815-822$.

(40) Canon, F.; Ballivian, R.; Chirot, F.; Antoine, R.; SarniManchado, P.; Lemoine, J.; Dugourd, P. Folding of a Salivary Intrinsically Disordered Protein upon Binding to Tannins. J. Am. Chem. Soc. 2011, 133, 7847-7852.

(41) Canon, F.; Ployon, S.; Mazauric, J.-P.; Sarni-Manchado, P.; Réfrégiers, M.; Giuliani, A.; Cheynier, V. Binding site of different tannins on a human salivary proline-rich protein evidenced by dissociative photoionization tandem mass spectrometry. Tetrahedron 2015, 71, 3039-3044. 